\section{VIRGILE project: The concept of virtual fire resistance facility for the assessment of construction products performance}

\author{
Gildas Auguin, Virginie Dréan \\ Research and Innovation Department, \\ Efectis France, Bordeaux, France
}

\begin{abstract}
Construction industries products have to satisfy fire safety regulation, including technical approvals in fire resistance, by tests in accredited laboratories. Fire resistance tests lay down on a complex protocol, in which full size samples are settled in large furnaces able to reproduce severe time-dependent fire curves. The full-scale mounting and the cost of such tests could be a constraint for their development. In that context, the concept of virtual facility has been developed by Efectis during the VIRGILE project. The use and development of numerical simulation tools are an interesting complement to the fire tests. The developed tool aims to model a fire resistance test including interaction between sample and fire test facility. The virtual facility allows to better analyze and evaluate a large number of technical alternatives in order to find the most efficient technical and economical solutions. Moreover, numerical simulations may improve the testing conditions including thermal stress control and metrology. This paper presents an overview of the main results and applications achieved during the VIRGILE project in ten years.
\end{abstract}

\section{Introduction}

New products developed by construction industries have to satisfy fire safety regulation. That includes technical approvals in fire resistance, for which the fire performance of products has to be assessed by tests in accredited laboratories. Fire resistance tests lay down on a precise and complex protocol, where full size samples are placed in large-scale facilities able to reproduce severe time-dependent fire curves or incident thermal loads. The fullscale mounting and the cost of such tests can be a brake for their development, because of the limitation of configurations that can be evaluated.

In this context, the concept of virtual facility has been developed by Efectis during the VIRGILE project since several years, where the use and development of numerical simulation tools are an interesting complement to fire tests. The developed tools aim to model a fire resistance test and to virtually recreate the thermal and, if necessary, the mechanical behavior of the tested product while integrating its interaction with the fire facility aggressions. Using a virtual facility allows better analyzing and evaluating a large number of technical alternatives in order to find the most efficient solutions in terms of technical and economical points of view, before, or in addition, performing a conclusive and certified fire resistance test. Moreover, numerical simulations may improve the testing conditions including thermal stress control and metrology.

This paper presents an overview of the main results and applications achieved during the VIRGILE project since 2009.

\section{Materials and Methods}

\section{Fire resistance furnace}

\section{Model development}

The first development addressed during the VIRGILE project concerned the numerical simulation of a fire resistance furnace to assess the thermo-mechanical behavior of vertical construction products. The vertical elements have to be tested in compliance with the European Standard EN1363$1^{1}$ where the thermal aggression program is the time dependent logarithmic curve ISO 834 defined in Eq. 1. In addition, the oxygen concentration must be maintained up to $4 \%$, and the static overpressure to $20 \mathrm{~Pa}$ at the top of the tested element for this furnace configuration.

$\theta=345 \log _{10}(8 t+1)+20$

Where $\theta$ is the temperature in ${ }^{\circ} \mathrm{C}$ and $\mathrm{t}$ is the time in minutes.

A numerical model of a vertical furnace, based on one of the Efectis laboratory furnace (Figure 1), has been achieved in 2009 with the computational fluid dynamics code Fire Dynamics Simulator (FDS) version 5 developed by the National Institute of Standards and Technologies. ${ }^{2}$

The 3D furnace volume was modelled with thermal characteristics of walls and soil materials representative of the existing furnace. Each gas burner has been modeled with cavities in which natural gas and air are injected in proportions based on ad-hoc calibration tests. An automatic regulation of the 12 gas burners combustion has been introduced to ensure the imposed exhaust volume flow through a chimney and the evolution of gas temperature. The time-temperature curve is controlled by six modelled plate thermometers designed and set as
Correspondence: Gildas Auguin, Research and Innovation Department, Efectis France, 19/21 Quai de Paludate, F-33800 Bordeaux, France.

Tel. +33.556.205.846.

E-mail: gildas.auguin@efectis.com

Acknowledgements: the VIRGILE project was supported by OSEO (French Ministries of Economy and Research) from 2008 to 2009. The PhD Thesis works on fire thermomechanical behavior of wooden-based doors were partly supported by the ANR10-EQPX-16 Xyloforest program.

Key words: Fire resistance; Virtual test; Wooden doors; Jet-fire; Façades.

Conference presentation: part of this paper was presented at the $5^{\text {th }}$ Iberian-LatinAmerican Congress on Fire Safety (CILASCI $5^{\text {th }}$ Congress), 2019, July 15-17, Porto, Portugal.

Received for publication: 30 August 2019

Accepted for publication: 23 September 2019.

This work is licensed under a Creative Commons Attribution 4.0 License (by-nc 4.0).

${ }^{\circ}$ Copyright: the Author(s), 2019

Licensee PAGEPress, Italy

Fire Research 2019; 3:72

doi:10.4081/fire.2019.72

required by EN1363-1. ${ }^{3}$ An iterative procedure has been implemented in the FDS source code to correct at each time step the fuel injected and the smoke exhaust in order to follow the ISO 834 curve.

Several calibration tests with inert construction products as light concrete or plasterboard walls were performed in order to verify the numerical model and the reliability of interface between the thermal aggressions simulated by FDS code and the heat transfer into the tested element calculated by the finite element model CASTEM. ${ }^{4,5}$ At each time step, radiative and convective heat fluxes received by the product and determined by the Computational Fluid Dynamics (CFD) code are imposed as boundaries conditions in the Finite Element Model (FEM) code to determine the walls temperatures, which becomes the new boundaries conditions in the CFD code at the next time step. ${ }^{4}$

The main parameters required by $\mathrm{EN}$ 1363-1, as temperature evolution, oxygen concentration and static pressure have been verified. So, the results in terms of gas temperature exhibit quite well comparison between predicted values and ISO 834 evolution (Figure 2). 


\section{Results and Discussion}

\section{Applications: wooden panels}

Several applications were performed for 10 years where plasterboards, ${ }^{5}$ woodenbased panels, ${ }^{6}$ composite sandwich panels ${ }^{7}$ and marine bulkheads ${ }^{8}$ were examined. For that, the VIRGILE methodology, based on a combined test-simulation approach with increasing complexity and scale, has been developed. Experimental analysis of the fire behavior of considered products was carried out at different levels, from the matter scale to the finished product scale.

The example of wooden-based panel fire behavior is discussed hereafter. This study was performed during a $\mathrm{PhD}$ thesis, ${ }^{6}$ where the main objective was to develop a numerical model able to simulate the fire thermomechanical behavior of woodenbased doors.

As improvement of the developed furnace model, an advanced thermal model has been developed in the FEM CASTEM model (developed by the Commissariat à l'énergie atomique et aux énergies alternatives) in order to consider the contribution of wood thermal degradation and combustion. The model allows taking into account the thermal degradation phenomena of wood (and wood-based products) at high temperatures (drying, pyrolysis and charring). The material thermal properties are locally calculated as a function of the solid thermal field, using a mixture law. Three different reactions are considered, namely the evaporation of water, the pyrolysis of wood and the combustion of pyrolysis gaz. These chemical reactions are driven by Arrhenius laws.

Fire tests were carried out with small scale panels (dimensions: $1000 \mathrm{~mm} \times 465$ $\mathrm{mm} \times 33 \mathrm{~mm}, \mathrm{~h} \times 1 \times \mathrm{p})$ exposed to the standard thermal loading (Figure 3 ).

The comparison between simulated and measured temperatures in a linen panel is discussed to evaluate thermal model. The results in terms of material temperature shown in Figure 4 present a general trend of the heat transfer to be well simulated by the advanced model. The thermal behavior around the vaporization process $\left(100^{\circ} \mathrm{C}\right)$ is difficult to reproduce. Nevertheless, the final temperature reached after 30 minutes at the non-exposed face of the sample (33 $\mathrm{mm}$ ) is similar experimentally and numerically both.

Coupled with the heat transfer model, an elastic mechanical 3D model (Figure 5) including the evolution of wood modulus of elasticity and the formation of charcoal permits to simulate the mechanical behavior of wooden elements.

\section{Specific fire resistance tests}

\section{Introduction: further developments of virtual facility tests}

Further developments have considered other specific fire resistance tests which can present an expensive cost of development and testing. The application of VIRGILE methodology implying virtual fire facilities sounds pertinent and adapted. Efectis focused on two kind of tests.

In order to answer to sustainable and low carbon footprint buildings develop-

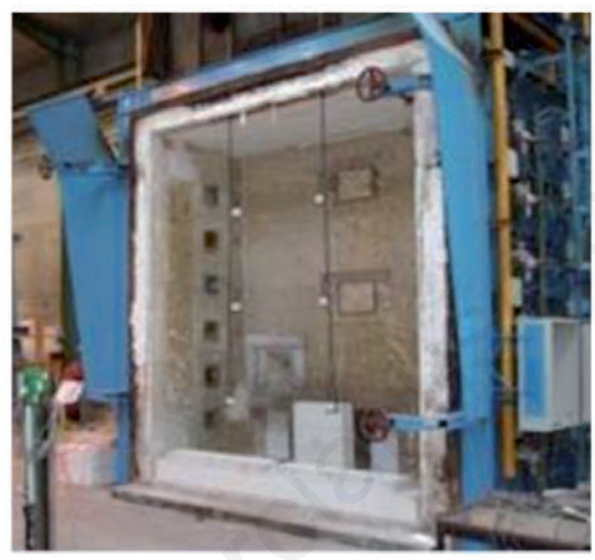

A

B

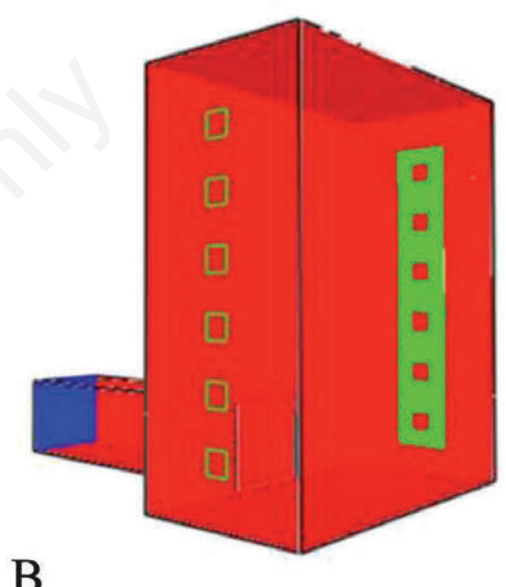

Figure 1. Vertical furnace settled in Efectis lab (Maizières-Lès-Metz) (A); virtual model (B).
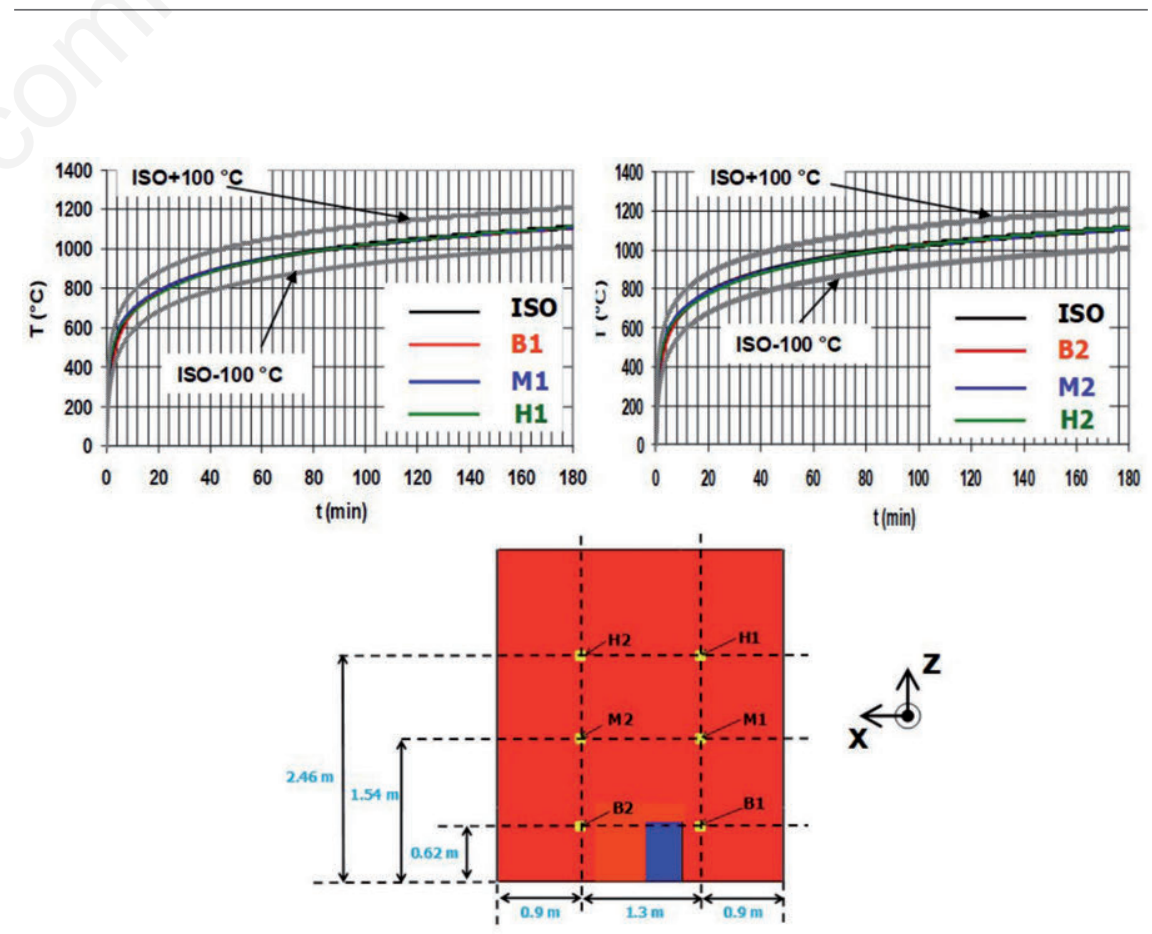

Figure 2. Comparison of plate thermometers temperature predictions vs International Organization for Standardization (ISO) 834 curve. ment, innovative external insulation sysems of façades are more and more come façades products are often nent and important fire safety issue that these construction products must still comply. In that way, Efectis performs certified resistance and reaction fire tests for façades ISO 13 785-1, BS 8414-1). A VIRGILE modology dedicated to façade tests was developed using numerical tools. An applifaçade fire propagation remains a perma- 
cation to the LEPIR2 French test ${ }^{9}$ is discussed in the section entitled Application to façade systems: LEPIR2 test.

In oil and gas industrial domain, the passive fire protection (PFP) performances for steel structure or equipment are assessed under specific and penalizing Standard tests. The jet fire standard ISO 22899-1 ${ }^{10}$ test consists in simulating the thermal and mechanical loads resulting from high-pressure releases of flammable gas, pressurized liquefied gas or flashing liquid fuels. Jetfires give rise to high convective and radiative heat fluxes as well as high erosive forces. To perform such a test and to validate a product performance is a great challenge for providers or manufacturers.

So, Efectis has developed a virtual jetfire using a CFD code which can reproduce the thermal aggressions of the facility. The jet fire testing application is discussed in the section entitled Application to oil and gas protection products: jet-fire test.

\section{Application to façade systems: \\ LEPIR2 test}

LEPIR2 facility aims to evaluate the fire behavior of external insulation systems implemented on façade according to the requirements given in the French Technical Specification 249 of the safety regulation. ${ }^{9}$ The system evaluation focuses on the risks of fire spreading by façades to upper levels. This facility involves a wood crib fire in the lower compartment of a full-scale two levels construction (Figure 6). Flames are venting outside from the fire compartment through windows openings and develop in front of the facade.
A numerical model of the LEPIR 2 facility has been developed with the CFD code FDS to reproduce fire development in the enclosure, as well as gas temperatures and heat flux on the tested façade for further evaluation of the fire performances of an external insulation solution. ${ }^{10,11}$

The first step was to develop and validate this virtual testing facility. The facility calibration was performed by considering any insulation system mounted on the concrete façade.

At this step, the main physical phenomena to model are the burning of wood cribs in the fire compartment, and the flames venting outside the openings and spreading along the façade. When experimental results are compared with numerical calculations, good agreement is found out for every quantity and each calibration test. For
A

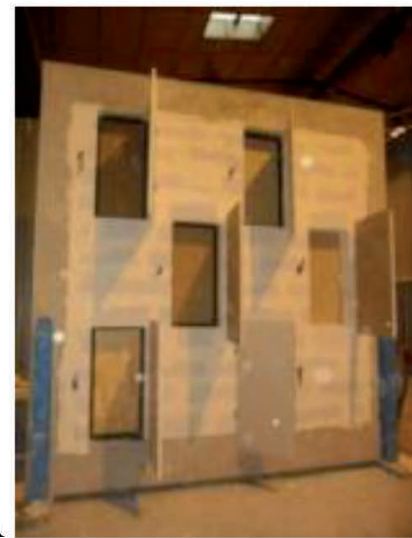

B

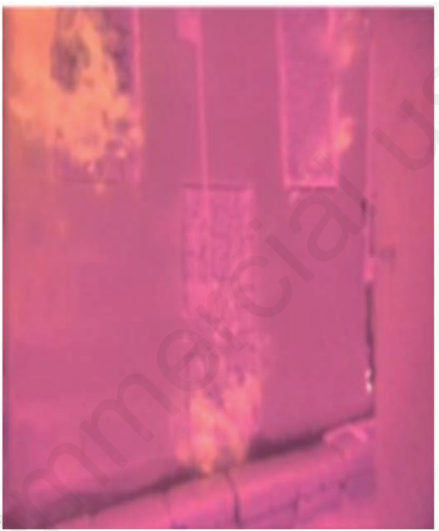

C

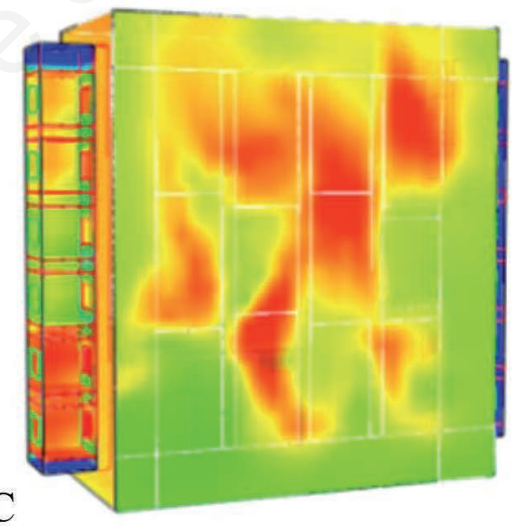

Figure 3. Wooden-based panels fire test. A) Apparatus. B) Fire. C) Wall temperature simulations.

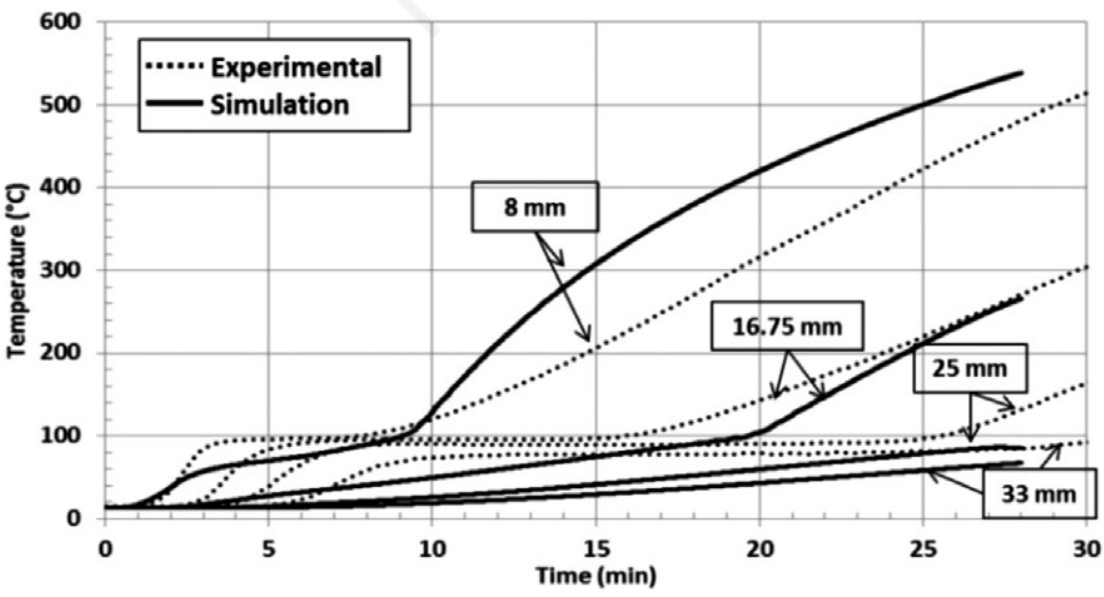

Figure 4. Simulated (solid lines) and measured temperatures (dotted lines) for the heat transfer in a linen fiberboard.

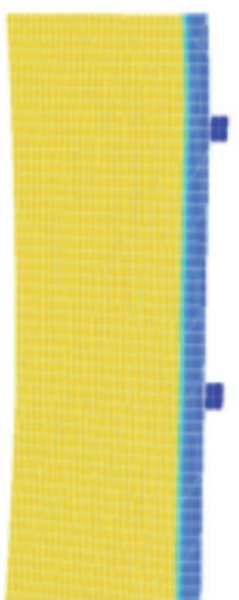

Figure 5. 3D numerical displacement (FEM CASTEM) of linen fiberboard. 
example, the gas temperatures in front of the façade at two levels are quite well comparable (Figure 7). The model gives also correct prediction of flames shape near the tested façade (Figure 6).

Thanks to this adapted tool, preliminary numerical simulations could be performed to optimize for example the thickness of insulation complex before a test. Comparisons of numerical results with real in-situ configurations have permit to validate constructive solutions that were out of Standard requirements.

A recent application has concern external ventilated façade insulation. For that, improvements of the Virtual LEPIR tool-box have been achieved ${ }^{12}$ where an analytical formulation of the thermal resistance for external system components has been introduced to approach the air layer behavior with thicknesses inferior to $100 \mathrm{~mm}$ that cannot be simulated easily in 3D CFD models.

\section{Application to oil and gas protection products: jet-fire test}

The jet-fire standard ISO 22899-1 ${ }^{10}$ consists in simulating the thermal and mechanical loads resulting from high-pressure releases of hot gas. In order to produce thermal and kinetic impact on a protected element, a $0.3 \mathrm{~kg} / \mathrm{s}$ release of gaseous propane is injected into a recirculation steel chamber, producing a fireball with an extended tail (Figure 8).

So, the jet-fire facility according to the ISO 22899-1 standard was modeled with the code $\mathrm{FDS}^{13}$ where the injection of propane is only modeled to reproduce the mass and heat flow imposed ${ }^{10}$ and the correct thermal loads close to the target.

Indeed, the region of lift-off near the gas nozzle cannot be properly described because of the low Mach-number approximation and diffusion flame model approach of the CFD code. Because it is not an elliptic phenomenon, there is no interaction of the flame zone to the lift-off area. So, the approximation and assumptions are sufficient to rightly describe thermal load on target.

The comparison of incident heat fluxes received by the tested panel at different locations in the recirculation chamber (upper part location shown in Figure 9) shows an acceptable agreement between experiment and numerical simulation. The thermal loads are quite correctly modeled to perform fire protection product evaluation.

The developed tool permits to design an optimal protection material thickness or to assess numerically several configurations of a given system. The idea is to model and validate a virtual mock-up of the required configuration based on a real fire jet test in order to assess several configurations by extrapolation.

\section{Conclusions}

Since 2009, Efectis has developed a concept of virtual fire resistance testing, the so-called VIRGILE methodology. This allows the numerical reproduction of the fire behavior of construction products during a real fire test performed in one of our facilities and following Standard requirements. The first objective of this methodology is to propose a helpful tool for manufacturers during development stage of a product or system, in order to perform only one conclusive real test. In addition, VIRGILE can be useful for validation of products or systems out of Standard or out of
A

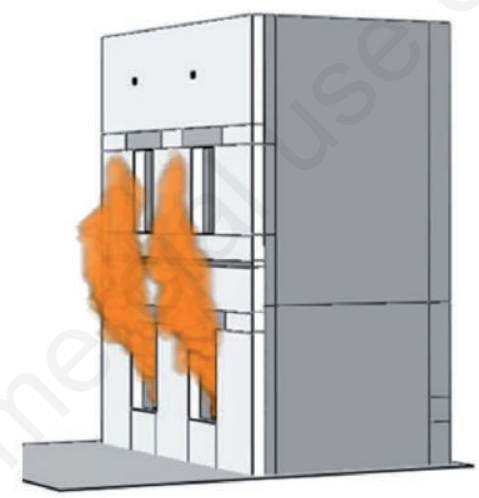

Figure 6. Calculated (A) and experimental (B) external flames in front of the façade during a LEPIR2 calibration test (Efectis, Les Avenières lab).

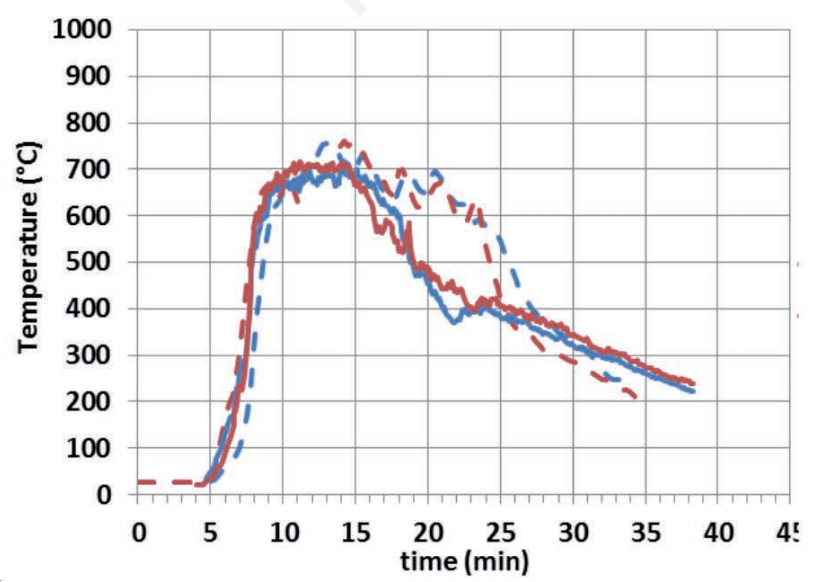

B

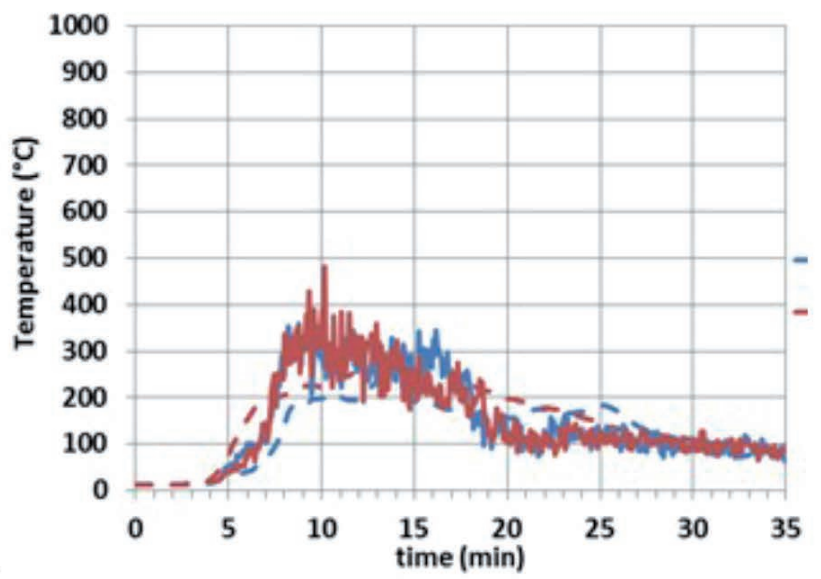

Figure 7. Comparison of experimental (dotted lines) and numerical (solid lines) gas temperatures for probes located $150 \mathrm{~mm}$ in front of the facade at (A) first level and (B) second level during 2 calibration tests with inert façade. 


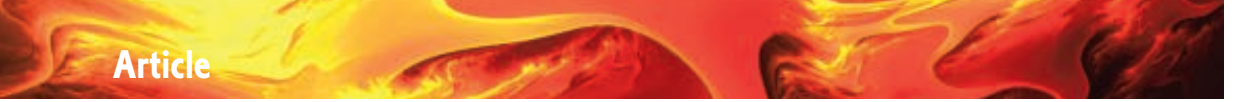

A
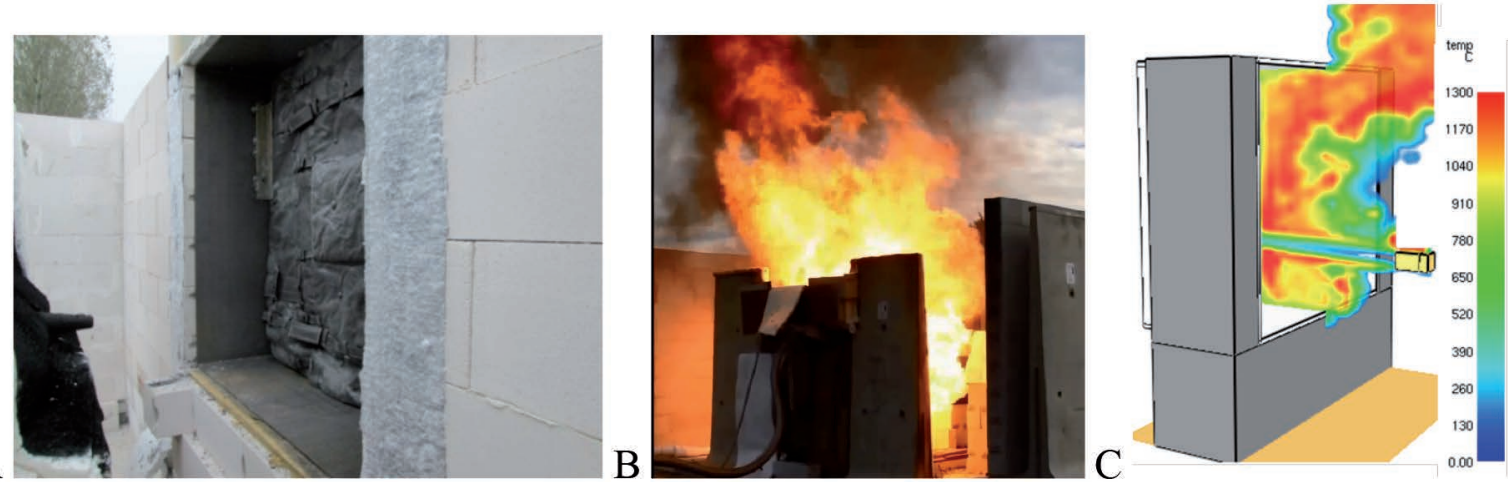

Figure 8. Jet-fire experimental facility (A), fire-ball phenomenon (B), predicted temperatures (C).
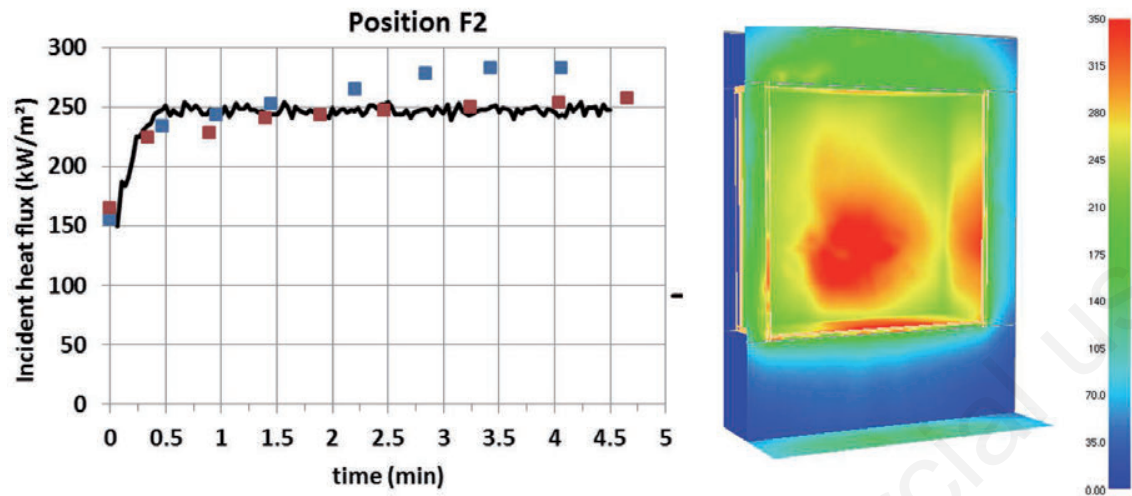

Figure 9. Experimental (point) and numerical (straight line) incident heat fluxes in the recirculation chamber.

validation domain application for expert assessments.

For that reason, a vertical furnace of Efectis has been modelled with the computational fluid dynamics code FDS to predict real thermal aggressions received by the tested elements. Iterative and coupled procedure with a FEM code permits to consider an implicit and real-time interaction between thermal aggressions and thermal response, even for combustible materials. An explicit and a posteriori procedure permits to calculate thermomechanical behavior if necessary.

Based on the same approach, other specific fire resistance facilities (LEPIR 2 for façades systems and the jet-fire for PFP resistance), which can present an expensive cost of development and testing, have been developed. A multi-scale approach through characterization and validation tests is necessary for each system to reliably calibrate and improve the original model.

Successful applications for fire resist- ance of construction products tested in case of furnace, full-scale façade test or jet-fire resistance exhibit encouragement for further development and applications.

\section{References}

1. AFNOR. EN 1361-1 Fire resistance tests - Part 1: general requirements. Brussels: CEN (European Committee for Standardization); 2013.

2. Mc Grattan K. Fire Dynamics Simulator (Version 5) Technical Reference Guide. National Institute of Standards and Technologies (NIST). NIST Spec Publ 2007;1018-5.

3. Sultan MA. Fire resistance furnace temperature measurements: plate thermometers vs shielded thermocouples. Fire Technol 2006;42:253-67.

4. Cayla F, Leborgne H. Fire resistance furnace simulator: thermal coupling between CFD furnace and FEM build- ing elements models. Proceedings of IDMME, Virtual Concept 2010, 2010 Oct 20-22, Bordeaux, France.

5. Tran H. Numerical and experimental study of fire behavior of plasterboard partitions on steel frame. $\mathrm{PhD}$ thesis, École Normale Supérieure de Cachan, France; 2012.

6. Cueff G. Development of a thermomechanical model on behavior of cellulose based materials under high temperature: application to the study of the woodbased door fire resistance. $\mathrm{PhD}$ thesis, France; 2016.

7. Auguin G, Barabinot P, Dréan V, et al. FLACOMARE, fire resistance of composite material: application to a sandwich panel. 21st French Congress of Mechanic, 2013 Aug, Bordeaux, France.

8. Dréan V, Cueff G. Fire performances of a marine bulkhead: numerical evaluation. 7th International Conference on Computational Methods in Marine Engineering MARINE 2017, 2017 May 15-17, Nantes, France.

9. Ministère de l'Intérieur \& Ministère de l'Equipement et du Logement. Arrêté du 10 septembre 1970 relatif à la classification des façades vitrées par rapport au danger d'incendie - Protocole d'application. In: Journal Officiel, 10/09/1970. Available from: https://www.legifrance.gouv.fr/affichTe xte.do?cidTexte $=$ LEGITEXT00000607 $4197 \&$ dateTexte $=20180523$

10. ISO (International Organization for Standardization). ISO 22899-1:2007: Determination of the resistance to jet fires of passive fire protection materials - Part 1: General requirements. Geneva, Switzerland: International Organization for Standardization; 2007.

11. Dréan V, Schillinger R, Leborgne H, et al. Numerical simulation of fire 
exposed façades using LEPIR II testing facility. Fire Technol 2018;54:943-66.

12. Dréan V, Schillinger R, Auguin, G. Assessment of an insulating air layer model of façade external system: contri- bution to fire simulation of facade performance fire test. J Phys Conf Ser 2018;1107:042004.

13. Auguin G, Dréan V, Guillaume E, Joyeux D. Numerical model of a jet fire facility for fire resistance protection passive assessments. 1st Conference on Protection Building \& Transportation systems Against Fire, 2016, May 18-19, Tehran, Iran. 